\title{
UNA OBRA INÉDITA DE JERÓNIMO ALEMÁN, PLATERO DE ISABEL LA CATÓLICA
}

Los Reyes Católicos han sido frecuente objeto de atención a lo largo del siglo xx por parte de gran número de historiadores ${ }^{1}$. Sin embargo fue en torno al año 1992, coincidiendo con la celebración del V Centenario del Descubrimiento de América y de la Reconquista de Granada, cuando se abordó en profundidad la imagen de los monarcas como mecenas de las artes y coleccionistas de objetos artísticos. Estos acontecimientos propiciaron diversas publicaciones con una metodología renovada ${ }^{2}$. Con parecidos enfoques, pero con mayor espacio para las artes decorativas, se acaban de clausurar las exposiciones de Valladolid, Madrigal de las Altas Torres y Medina del Campo, que conmemoraban los 500 años de la muerte de la reina Católica y que han dado lugar también a la edición de importantes trabajos ${ }^{3}$.

Paralelamente, el desarrollo de los estudios de platería en las universidades españolas y el progresivo aumento de la bibliografía especializada ${ }^{4}$ permitieron en el año 1992 organizar una exposición monográfica sobre la platería en la época de estos monarcas ${ }^{5}$. En el catálogo correspondiente se hizo entonces un completo estado de la cuestión en el que se llegaron a recoger casi un centenar de plateros, que trabajaron sistemática o esporádicamente para los Reyes, y se mencionaron numerosas obras que pertenecieron a los soberanos ${ }^{6}$. La mayoría de estas piezas han desaparecido y se desconoce su autor, pero todavía se conserva la custodia portátil del maestro Jaime Aimerich o Almeriche, hecha entre 1495 y 1499, que fue vendida en 1505 en la testamentaría de la Reina al cabildo de la catedral de Toledo y que hoy se guarda en el interior de la custodia de asiento que Enrique de Arfe labró para la Catedral Primada ${ }^{7}$. De igual manera han llegado a nuestros días algunas de las obras que Isabel donó a la Capilla Real de Granada, como el famoso espejo, de posible origen italiano, luego transformado en custodia, así como el cáliz y el portapaz, tradicionalmente atribuidos a Pedro Vigil, y el cofre decorado con bestiones y hojarasca ${ }^{8}$. Todas ellas se comentaron y se reprodujeron, aunque no se pudieron incorporar entonces en el catálogo de la exposición. En cambio sí se logró reunir para esta ocasión un espléndido conjunto de 126 obras de la época, procedentes de muchos puntos

\footnotetext{
${ }^{1}$ Cito, como ejemplo, el clásico estudio de I. Brans: Isabel la Católica y el arte hispano flamenco, Madrid 1952 y A. de la Torre del Cerro: Testamentaría de Isabel la Católica, Barcelona, 1974.

${ }^{2}$ Véase el Catálogo de la Exposición Reyes y Mecenas. Los Reyes Católicos - Maximiliano I y los inicios de la Casa de Austria en España, Toledo, 1992. También J. Yarza Luaces: Los Reyes Católicos. Paisaje artístico de una monarquía, Barcelona, 1993. Ambos con importantes capítulos sobre mecenazgo y coleccionismo y con abundante bibliografía específica.

3 De manera especial en los capítulos de A. Sáenz de Miera: «Instrumentos suntuarios para una nueva dignidad real: útiles y objetos preciosos pertenecientes a Isabel la Católica» y L. Arbeteta: «La «Corona Rica» y otras joyas de estado de la reina Isabel», en Arte y cultura en la época de Isabel la Católica, Valladolid, 2003. Aún queda pendiente el Congreso Internacional sobre «Isabel la Católica y su época» que tendrá lugar el próximo mes de septiembre en Valladolid, Barcelona y Granada.

${ }^{4}$ Cito como ejemplo las tesis doctorales de J. C. Brasas Egido: La platería Vallisoletana y su difusión, Valladolid, 1980, M a V. Herráez Ortega: Enrique de Arfe y la orfebrería gótica en León, León, 1988, o A. Barrón García: La época dorada de la platería burgalesa, Burgos, 1998, J. M. Cruz Valdovinos: «Platería», en Historia de las artes aplicadas e industriales en España, Madrid, 1982, pp. 73-8, entre otras varias.

5 J. M. Cruz Valdovinos: Platería en la época de los Reyes Católicos, Madrid, 1992.

${ }^{6}$ Muchos de los datos proceden de la almoneda de la Reina Católica que publicó A. de la Torre del Cerro: Testamentaría..., sobre todo pp. 34 en adelante.

${ }^{7}$ J. M. Cruz Valdovinos: Platería en la época..., p. XXXVII-XXXIX y A. Escalera Ureña: «La custodia interior de la gran custodia procesional de la catedral de Toledo. Datos encontrados durante su restauración», en Tipologías, talleres y punzones de la orfebrería española, Zaragoza, 1982, pp. 101-106. Las cuentas fueron publicadas por A. de la Torre y E. A. de la Torre: Cuentas de Gonzalo de Baeza, tesorero de Isabel la Católica, CSIC, Patronato Menéndez Pelayo, 1955, p. 274.

${ }^{8}$ J. M. Cruz Valdovinos: Platería en la época..., pp. XXXVI-XXXVII. Sobre el cetro y la corona conservados en la Capilla Real pueden consultarse también los comentarios de A. Sáenz de Miera y de L. Arbeteta citados en la nota 2.
} 
de la geografía española. Pero la mayoría de estas piezas se relacionan con personalidades contemporáneas de la nobleza o de la iglesia y sólo la custodia de Támara, labrada por el burgalés Juan de Santa Cruz, y el cáliz del monasterio de San Juan de Corias en Cangas de Narcea (Asturias) fueron donados por los propios monarcas ${ }^{9}$.

Es decir, a pesar de los importantes esfuerzos que se han realizado hasta el momento, todavía nos queda mucho por conocer sobre la plata y plateros de la Reina Católica. Por esta razón nos parece oportuno añadir una nueva obra y algunos datos inéditos relacionados con los plateros reales en torno a $1500{ }^{10}$.

En el museo de la catedral de Toledo se guarda un hermoso acetre de plata sobredorada, martillada, repujada, cincelada, calada y fundida. Tiene forma de caldero con asa y es pieza de calidad espléndida y de cronología excepcional, ya que es el único de los tiempos de la Reina Isabel que ha llegado a nuestros días (Fig. 1) ${ }^{11}$. El inventario de 1989, donde se reprodujo por primera vez, describe su traza y decoración como «cubo en forma de cestillo, de plata ligeramente dorada, superficie ondulada formando seis lóbulos y riquísimamente repujada y cincelada con figuras de tritón, león, centauro, grifo, fauno y dragón entre follajes y cintas con botones y cordones, borde y pie calados, asa sujeta con argollas como tallos enroscados. Arte gótico del tiempo de los Reyes Católicos, posiblemente toledano» ${ }^{12}$. Cruz Valdovinos lo mencionó después escuetamente como una pieza de calidad, de hacia 1490, con adorno de bestiones ${ }^{13}$.

Por último, hace varios años que yo misma lo relacioné con un grupo de obras labradas en la Península en torno a 1500 por artífices de origen germánico o por plateros peninsulares que reinterpretaban modelos centroeuropeos ${ }^{14}$. Esta opinión enlazaba con la tesis defendida por Hernmarck en 1977, según la cual algunas obras conservadas en España, como el jarro de la Sierpe de la catedral de Sevilla, hecho hacia 1500 pero comprado por el cabildo hispalense al obispo de Burgos en 1564 y considerado tradicionalmente portugués en relación con varias piezas del Museo de Coimbra y del palacio de Ajuda en Lisboa, podían ser, en realidad, de origen centroeuropeo, dado su extraordinario parecido con algunos diseños y jarros germáni$\cos ^{15}$. Me faltaba confirmar esta hipótesis a través de algún documento o mediante la interpretación de sus marcas, así como señalar las posibles fuentes de inspiración de sus temas ornamentales y las circunstancias de su llegada al museo de Toledo.

El acetre es, efectivamente, una hermosa pieza repleta de bestiones y hojarasca de abultado relieve, que le prestan riqueza y opulencia. La procedencia de algunos motivos decorativos, como las cintas enrolladas de forma helicoidal y las hojas vegetales, parecen inspirados en placas decorativas de Isrhael van Meckenem; las aves rapaces de los lóbulos de la base se ase-

\footnotetext{
${ }^{9}$ El cáliz y la custodia se recogen en los dos primeros números del catálogo de la citada exposición sobre Platería en tiempos de los Reyes Católicos... Respecto a las piezas de la Capilla Real, parece acertado considerar donación de la Reina el cofre con bestiones, el espejo, el portapaz y el cáliz, estos dos últimos atribuidos tradicionalmente al platero Pedro Vigil, pero no el cetro y la corona.

${ }^{10} \mathrm{Mi}$ interés por este tema se despertó a través del encargo que me hizo la Sociedad Estatal de Conmemoraciones Culturales para el catálogo de la exposición Isabel la Católica: La magnificencia de un reinado que, finalmente no se pudo incorporar en el texto.

${ }^{11}$ Se conservan varios de la primera mitad del XVI, como el del Victoria and Albert Museum de Londres recogido por CH. Oman: The golden age of hispanic silver, Londres, 1969, núm. 33, fig. 31 ó el de la catedral de Pamplona que dimos a conocer en M. C. García Gainza y M. C. Heredia Moreno: Orfebrería del Museo Diocesano de Pamplona, Pamplona, 1978, entre otros.

${ }^{12}$ M. Revuelta Tubino y otros: Inventario artístico de Toledo, T. II. La Catedral Primada (Vol. II), Toledo, 1989, p. 263, fotos núms. 283 y 327 . Es de plata blanca y sobredorada, repujada y cincelada. Mide $31^{\prime} 3 \mathrm{~cm}$ de alto y 26 y $28^{\prime} 7 \mathrm{~cm}$ de diámetro.

13 J.M. Cruz Valdovinos, «Platería», Las artes decorativas en España (Tomo II), Madrid, 1999, p. 534.

${ }^{14}$ M.C. Heredia Moreno, «La platería germánica en España en la época del Emperador y la repercusión de los modelos centroeuropeos en la Península», en El arte de la plata y de las joyas en la España de Carlos V, La Coruña, 2000, p.112.

${ }^{15}$ C. Hernmarck: The art of european silvershmith, Londres, 1977, T. II, p. 231.
}

AEA, LXXVIII, 2005, 309, pp. 83 a 105 

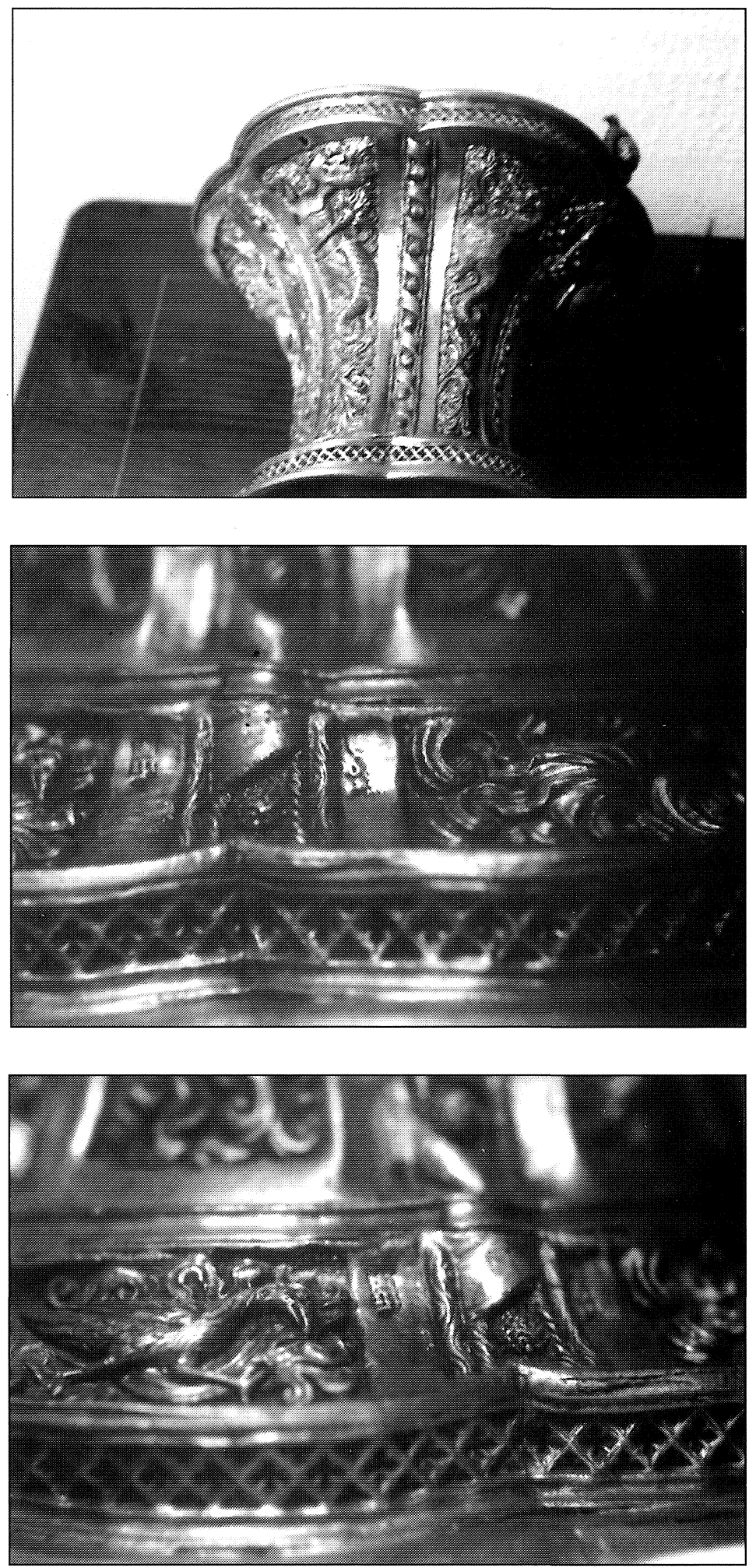

Fig. 1. Acetre. Museo Catedral de Toledo.

Fig. 2. Acetre. Marcas.

Fig. 3. Acetre. Marca. 
mejan a las de algunas estampas del Maestro de la Pasión de Berlín ${ }^{16}$ y los temas y composición de los distintos campos lobulados del cuerpo recuerdan a las placas oblongas de este mismo maestro, a estampas del alfabeto gótico del Maestro ES y a las imágenes de las estampas de naipes, que alcanzaron gran difusión por toda Europa ${ }^{17}$. Por otra parte, la traza, el tipo de composición y la técnica se relacionan también con las vinajeras de la capilla del Condestable de la catedral de Burgos, obra anónima labrada hacia 1487, que se ha comparado repetidas veces con la fuente de esta misma institución marcada por el artífice Juan de Burgos ${ }^{18}$.

Pero el acetre conserva tres marcas impresas en los lóbulos de la base. La del escudo con tres gallardetes ondeantes, muy borrosa, puede ser la de Valladolid y la nominativa «o(o)/ P(A)», en góticas, situada bajo ella, la del marcador Pedro Alonso (Fig. 2). Ambas se repiten en la sacra contemporánea de la catedral de Toledo. La tercera marca, de difícil lectura, nos parece la misma que la de la naveta de la capilla del Condestable con relieves de Adán y Eva y la interpretamos como «gm» o «gmo» en góticas, enlazadas y bajo corona, por lo que debe corresponder a un platero real (Fig. 3) ${ }^{19}$. Por otra parte, las tres marcas del acetre son idénticas a las de la cruz procesional del museo diocesano de Palencia que Seguí González publicó en el año 1990, adjudicando la de la corona, entonces inédita, al artífice Jerónimo Alemán, vecino de Valladolid, que recibió ciertos pagos de Isabel la Católica en el año $1504{ }^{20}$. Aunque no se indica la procedencia, suponemos que este último dato se refiere a las cantidades cobradas por el platero entre 1502 y 1504 «por ciertas obras para la reina y el salario de 91 días por tasar y pesar joyas de su cámara» ${ }^{21}$. Además, en mi opinión este maestro podría identificarse con el platero Jerónimo de Bruselas estante al año siguiente en Valladolid al servicio de la reina Juana $^{22}$.

Por todos estos detalles, considero que el acetre lo labró para Isabel un platero real de origen germánico, conocido como Jerónimo Alemán o Jerónimo de Bruselas ${ }^{23}$. Es posible que llegase a España en 1496 en el séquito de Margarita de Austria cuando vino a contraer matrimonio con el príncipe don Juan, primogénito de los Reyes Católicos, o quizás viniese en 1502 cuando las Cortes de Castilla juraron en Toledo acatamiento a la princesa Juana y a su marido Felipe el Hermoso, si es que no residía en la Península desde años antes. En cualquier caso, el acetre es una nueva obra a añadir al catálogo, todavía exiguo, del artífice, integrado, por el momento, sólo por la cruz procesional del Museo Diocesano de Palencia y, quizás, por la naveta de la Capilla del Condestable de la catedral de Burgos. La calidad de las tres piezas muestra la mano de un maestro de primera fila, pero el acetre es la única decorada con bestiones, cuya abultada técnica lo acercan, por otra parte, a las citadas vinajeras de la capilla del Condestable. Incluso la traza hexalobulada del cuerpo repite, aunque invertida, la estructura del pie de las jarritas.

\footnotetext{
${ }^{16}$ R. Berliner: Motivos ornamentales e los siglos XV al XVIII, Barcelona, s/f, láms. 10-3 y 3-2.

17 The Illustrated Bartsch 8 formerly, volume 6 (Parte 1). Early German Artists, Nueva York, 1980, pp. 90-108 (láms. 92-113,1) y 116-122 (láms. 124-130).

${ }_{18}$ M. A. Zalama: «Vinajeras de los Condestables de Castilla», en Reyes y Mecenas..., p. 336. A. Barrón García: La época dorada de la platería burgalesa, Burgos, 1998, T. I, pp. 119 y 187-189, y «Vinajeras», en El arte de la plata..., núm. 15. J. M. Cruz Valdovinos: Platería en la época..., núms..6 y 7.

${ }^{19}$ Las marcas de la sacra y de la naveta están reproducidas en el citado catálogo sobre la Platería en la época..., núms. 6 y 38

${ }^{20}$ M. Seguí González: Catálogo de Platería del Museo Diocesano de Palencia, Palencia, 1990. pp. 21-22 y núm. 12.

${ }^{21}$ Los publicó A. Prieto Cantero: Casa y descargo de los Reyes Católicos, Instituto «Isabel la Católica» de Historia Eclesiástica. Valladolid, 1969, leg. 3, f. 437. Después lo recogieron sucesivamente J. M. Azcárate: «Sentido y significación de la Arquitectura Hispanoflamenca en la corte de Isabel la Católica», Boletín del Seminario de Arte y Arqueología de la Universidad de Valladolid, 1971, p. 203 y J. C. Brasas Egido: La platería vallisoletana..., p. 132.

${ }^{22}$ A.G.S. Casas y Sitios Reales. Casa de la Reina Juana 2, p. 7.

${ }_{23}$ Recordemos que, según I. Brands: Arte hispanoflamenco..., p. 50, nota 12, a los artistas centroeuropeos se les denominaba genéricamente «alemanes».
}

$A E A$, LXXVIII, 2005, 309, pp. 83 a 105 
Además, el acetre tuvo que realizarse o, al menos, marcarse en Valladolid en la década de los años noventa y después, por donación o por compra, pasó a la catedral de Toledo. En la almoneda de la Reina efectuada en 1505, entre las joyas de oro y plata que Juan Velásquez y Baltasar de San Román recibieron del camarero Sancho de Paredes figura «Un açetre grande de plata labrado de synzel de vnos follajes grandes de vnas letras moriscas y el asa retorçida e dos cabezas de leones en donde se açe el asa, todo de plata dorada, que peso doçe marcos y 4 onças 6 ochavas, estava apreçiada la hechura de cada marco a mill mrs. E de oro cada marco 2 ducados, con su caxa e funda. Vendiose al Cardenal dEspaña en 31.375 mrs. Fechura» ${ }^{24}$.

La descripción no coincide exactamente con el ejemplar que ha llegado a nuestros días, pero ciertos detalles, como las cabezas de leones del asa, pueden haber desaparecido a lo largo del tiempo. De hecho, el asa, lisa y sin dorar, que hoy ostenta la pieza parece añadida. En cuanto a las «letras moriscas», habría que interpretarlas como una referencia genérica a la ornamentación de animales fantásticos entre hojarasca. Recordemos que los bestiones del acetre evocan las letras del abecedario del Maestro ES, que con frecuencia utilizaron los plateros de la época, y que una acepción del término «morisco» es la de «dibujo o motivo ornamental formado por follajes caprichosos» ${ }^{25}$. Es decir, la descripción podría aludir de forma general al tipo de decoración caprichosa, desordenada y de carácter profano, que nos indica, por otra parte, su primitiva función de pieza civil. Sin embargo, el hecho de que en la testamentaría de Isabel ya se cite la pieza como acetre y no como un simple caldero parece indicar también que se venía utilizando con finalidad religiosa desde años atrás, quizás para el servicio del oratorio de la propia reina.

Hay que tener en cuenta que el cambio de uso y las transformaciones de piezas civiles o religiosas para adecuarlas a una nueva funcionalidad religiosa no eran infrecuentes. En el año 1504 Juan Pizarro, otro conocido platero de la Reina Católica, recibió 15 cruzados de oro por «dorar una copa que se hizo custodia» y Martín Salinas, platero de la princesa Juana, hizo una Magdalena de una Virgen y del Niño una copa para ponérsela en la mano. Al año siguiente fue el platero Diego de Ayala el que cobró por el escudo real que había puesto en un cofre de plata dorada procedente de la testamentaría del cardenal don Diego Hurtado de Mendoza ${ }^{26}$. Sería interesante poder llegar a demostrar que este cofre fue el que la Reina donó, a su vez, a la Capilla Real de Granada, pero carecemos de datos sobre este asunto.

Carmen Heredia Moreno

(Universidad de Alcalá)

\footnotetext{
24 A. de la Torre y del Cerro: Testamentaría de Isabel..., p. 37.

${ }^{25}$ Es uno de los significados del término según la Nueva Enciclopedia Larousse, Barcelona, T. XIII, p. 6736.

${ }^{26}$ A. Prieto Cantero: Casa y descargo..., legajo 4, f268 y legajo 5, f. 349.
} 